\title{
CRUZANDO OS CAMINHOS DA ECONOMIA SOLIDÁRIA E DO FEMINISMO: PASSOS PARA UMA CONVERGÊNCIA NECESSÁRIA
}

\author{
ISABELLE HILLENKAMP ${ }^{\mathrm{I}}$, ISABELLE GUÉRIN ${ }^{2}$, CHRISTINE VERSCHUUR ${ }^{3}$ \\ IRD-CESSMA, aSSOciada ao PPGS-UFSCAR ${ }^{1}$, IRD-CESSMA ${ }^{2}, I H E I D^{3}$
}

Recepción manuscrito: 6 de enero de 2017

Aceptación versión final: 15 de abril de 2017

\begin{abstract}
RESUMO Esse artigo pretende contribuir para o diálogo entre a economia solidária (ES) e os estudos feministas através da identificação das principais categorias e escalas utilizadas na análise da ES, por um lado, e nos estudos feministas sobre as organizações de mulheres e suas práticas econômicas, sociais e políticas, por outro lado. Este diálogo chama a atenção para a forma em que as relações de produção e de reprodução social se articulam dentro da Es e mostra como as práticas de es renovam o econômico e o político, entendidos aqui como categorias tanto de ação quanto de análise.
\end{abstract}

PALABRAS CLAVE Economía solidaria, feminismo.

ABSTRACT This article aims to contribute to the dialogue between the solidarity economy (SE) and feminist studies by identifying the main categories and scales used in SE analysis, on the one hand, and in feminist studies on women's organizations and their economic, social and political practices, on the other hand. This dialogue draws attention to the way in which the relations of production and social reproduction are articulated within SE and shows how SE practices renew the economic and the political, understood here as both categories of action and thought.

KEYWORDS Solidarity economy, feminism.

JEL CODES R13, J16.

\section{INTRODUÇÃO}

As mulheres são majoritárias em várias iniciativas de economia solidária, tanto em países do hemisfério norte quanto do sul. ${ }^{1}$ Seja em grupos de produção artesanal, agrícola, de troca local, de finanças solidárias, em associações comunitárias, no trabalho em cooperativas ou em sociedades mutualistas, as mulheres estão geralmente sobre-representadas. Isso indica que a economia solidária é — como qualquer economia - atravessada pelas relações de gênero, e levanta questões fundamentais como: poderiam as mulheres encontrarem na economia solidária um

Artículo no original. Adaptado de Hillenkamp, I., Guérin, I. y Verschuur, C. (2014). Economie solidaire et théories féministes: pistes pour une convergence nécessaire. Revista de Economia Solidária, 7, 5-43. 
caminho para a emancipação? Ou seria a solidariedade entre mulheres, muitas vezes subalternas, reprodutora de mecanismos da sua própria exploração?

Surpreendentemente, os estudos sobre a economia solidária (ES) até o momento, se interessaram muito pouco por questões de gênero e teorias feministas. É certo que existe uma dificuldade em se referir a estes estudos no geral, tanto eles estão enraizados em contextos específicos e são atravessados por influências diversas. No entanto, fora algumas exceções, a maior parte dessas análises não incorporam a categoria de gênero. Na melhor das hipóteses, os atores-atrizes e pesquisadores-as desse campo se limitam em afirmar que as diferenças entre os sexos devem ser levadas em conta e que a igualdade de gênero é um objetivo da economia solidária. Nos países onde a cooperação para o desenvolvimento tem um papel importante, as abordagens dominantes de "gênero e desenvolvimento» acabaram fortalecendo a visão simplista de que a economia solidária funcionava necessariamente a favor das mulheres.

Paralelamente, a economia feminista denuncia há muito tempo o viés masculino das ciências econômicas, questionando os seus modelos, métodos e valores subjacentes; revisitando suas categorias de análise, sobretudo a ausência do trabalho reprodutivo; ressaltando a multiplicidade de motivações que subjazem a ação; e considerando que tanto o gênero e a raça, enquanto construções sociais, quanto as relações sociais de gênero, classe e raça se inscrevem nas relações econômicas (Castro-Gomez e Grosfoguel, 2007). Os/as sociólogos/as e antropólogos/as feministas também estudaram no âmbito local diversas organizações de mulheres e suas práticas econômicas, sociais e políticas. Contudo, as categorias de análise feminista são raramente interligadas com aquelas da economia solidária. Esse artigo afirma que de um lado a economia solidária e de outro a economia, a sociologia e a antropologia feministas seguiram caminhos diferentes ao desenvolverem-se, limitando assim as possibilidades para uma reflexão transversal. Esses marcos estão longe de serem opostos e, as abordagens se sobrepõem no estudo das mesmas práticas. Entretanto, essas em geral não dialogam e acabam não produzindo uma reflexão articulada ao redor de categorias compartilhadas.

Esse artigo tem como objetivo contribuir para a emergência desse tipo de reflexão através da identificação das principais categorias e escalas utilizadas na análise da economia solidária (parte 1) e nos estudos feministas sobre as organizações de mulheres e suas práticas econômicas, sociais e políticas (parte 2). Sobre esta base, indicamos caminhos para uma reflexão transversal (parte 3). É importante ressaltar a amplitude desses dois campos: o da economia solidária e o das teorias feministas. No presente artigo, tratamos de ressaltar os debates centrais e seus pontos de convergência e de divergência, e não de dar conta das nuances e variações introduzidas pelos(as) múltiplos(as) atores/atrizes de cada um dos campos.

\section{DEBATES CENTRAIS NA ECONOMIA SOLIDÁRIA E POSSÍVEL APROXIMAÇÃO COM O FEMINISMO}

\section{O VALOR DO LOCAL COMO POSTURA EPISTEMOLÓGICA}

Se a economia solidária é fruto de influências tão diversas quanto o cristianismo social, a teologia da libertação, o socialismo utópico e ainda a crítica do sistema-mundo capitalista, um 
dos seus fundamentos principais é o enraizamento local da ação e da observação. Contestando as relações de produção capitalista, ao mesmo tempo em que se distanciam das teses do socialismo centralizador, os/as atores/atrizes da economia solidária têm o nível local como escala indispensável, ainda que não única, para consolidar as iniciativas na sociedade civil. Na Europa e na América do século passado, os projetos socialistas associativos de Pierre Leroux, Charles Fourier ou Robert Owen apoiaram a organização de produtores em grupos autônomos livremente federados. A renovação da economia solidária na Europa e na América do Norte nos anos 1970 acontece graças ao envolvimento dos(as) cidadãos(ãs) que reconstruiram um vínculo social concreto através de iniciativas, como por exemplo, os serviços de proximidade, os sistemas de troca, a autoprodução ou as cantinas coletivas (Eme e Laville, 2006). Na América Latina o «Fator C» - cooperação, comunidade, colaboração- foi reconhecido como o fundamento da economia de solidariedade (Razeto, 1997) e a economia popular, que se baseia na utilização pelos grupos populares da sua própria força de trabalho e dos recursos disponíveis localmente para satisfazer suas necessidades materiais e imateriais (Sarria, Icaza e Tiriba, 2006), é considerada como um terreno fértil para a economia solidária.

Convém clarificar que se a economia solidária é enraizada no nível local, ela não visa um localismo, concebido como uma muralha contra agressões exteriores, como aquelas causadas pela mundialização neoliberal. Se os atores da economia solidária criticam essa mundialização, eles geralmente situam suas práticas dentro de um projeto de formas alternativas de conexão e interdependência, e não em uma utópica desconexão com o mundo. Nessa perspectiva, o significado das práticas locais na economia solidária deve ser analisado de maneira sistemática, considerando o lugar dessas práticas na interação com a economia capitalista e a pública (Coraggio, 2010) e a capacidade da economia solidária em estabelecer as bases de novas relações sociais, tanto no plano material quanto no plano subjetivo (Quijano, 2008).

Tanto as experiências quanto as perspectivas teóricas são diversas e se tornaram, sem dúvida, mais complexas desde a mundialização dos anos 1980. A verdade é que tanto para os atores, quanto para os pesquisadores, a escala local continua indispensável para diferenciar a organização solidária e suas relações de produção, de uma empresa capitalista. Essa diferenciação é feita na economia solidária através das formas singulares e muitas vezes inovadoras de organização do trabalho, de posse dos meios de produção e de tomada de decisões. Mais do que um enfoque estreito no local enquanto nível de ação, o resultado é uma postura epistemológica que reconhece o valor do local e privilegia essa escala de observação para apontar a especificidade de práticas que são ignoradas na análise da escala macroeconômica, dominante nas diversas correntes das ciências econômicas.

Uma vez que essa postura rechaça o determinismo, mas leva em consideração a diversidade da economia real (Gibson-Graham, 2005) e as identidades, valores e lógicas dos atores, ela tem a possibilidade de se deparar com as práticas solidárias, onde as mulheres representam a maioria, e entender as suas lógicas. No entanto, a prioridade dada à contestação do capitalismo na economia solidária conduziu, até agora, à uma análise dessas práticas sob o ângulo do estabelecimento de novas relações de produção, sem incluir a reflexão sobre a maneira como as relações de gênero estão nelas articuladas. As intersecções entre as categorias de gênero, classe, raça e/ou etnia, destacadas nos estudos feministas, continua sendo pouco 
integrada nesse campo de análise.

PRINCÍPIOS DE UMA ECONOMIA PLURAL

A vontade de construir relações de produção não capitalistas, colocou a questão da conceptualização e das modalidades de realização de uma economia plural no centro das reflexões sobre a economia solidária. Quais condições permitem o desenvolvimento das práticas solidárias em um meio ambiente institucional dominado pelos princípios de mercado, pela lógica da acumulação capitalista, pela contradição entre capital e trabalho e pela ideologia do homo oeconomicus? Precisamente, quais são os princípios da economia solidária, como eles podem se articular aos princípios dominantes das instituições de regulação macroeconômicas e qual é a capacidade instituinte da economia solidária?

Os trabalhos de Marcel Mauss, especialmente o Ensaio sobre o Dom (Mauss, 1968 [1923]) que contesta as leis supostamente naturais do utilitarismo, e os trabalhos de Karl Polanyi, especialmente A Grande Transformação (Polanyi, 1983 [1944]), que aponta para a singularidade histórica e o caráter utópico de um mercado autorregulado, foram considerados as bases de uma teoria sobre a economia plural (Laville, 2013). Na sequência de Mauss, a lógica do dom e do contra-dom e de sua tríplice obrigação de dar, devolver e receber foi considera como um fundamento da economia solidária. O enfoque dado à obrigação possibilitou superar as aporias que resultam da assimilação da solidariedade a uma lógica de interesse dissimulado ou de desinteresse. Todavia, a visão do dom, sobretudo quando limitada a uma esfera de práticas isolada do princípio de mercado, não permite considerar o entrelaçamento entre os princípios de ação e as instituições na economia solidária, e acaba o conduzindo também à aporias (Wanderley, 2013).

Atualmente, a visão de uma economia plural fundada de maneira sincrônica nos quatro princípios de integração econômica identificados por Polanyi (1983, [1944], cap. 4), ou seja, a reciprocidade, a redistribuição, a autossuficiência ${ }^{2}$ e o mercado, torna-se cada vez mais importante em diversos trabalhos sobre a economia solidária. As nuances existem conforme os princípios são entendidos como modalidades de mobilização de recursos (Lemaitre, 2013), como modos de organização econômica associados a diferentes modelos institucionais - respectivamente a simetria, a centralidade, a autarquia e o mercado (Vázquez, 2013) -, ou ainda como princípios de interdependência entre os quais a reciprocidade, que se funda sobre diferentes tipos de complementaridade instituídos, caracteriza a economia solidária (Servet, 2013). Apesar dessas nuances, esse enquadramento é considerado como adequado em diversos trabalhos para abordar a questão central da articulação entre as práticas solidárias fundadas em um princípio de reciprocidade, o princípio de mercado associado ou não à lógica capitalista, a redistribuição assegurada pelo Estado ou por instâncias públicas ou privadas em diferentes níveis e o princípio de autossuficiência, predominante, sobretudo nas unidades domésticas da economia popular (Coraggio, 1998; Hillenkamp, 2013).

Este enquadramento da economia «substantiva» e "plural» de Karl Polanyi revela e legitima de fato diferentes formas de produção e de circulação de bens e serviços, sejam elas monetárias e mercantis ou não (Degavre e Lemaître, 2008). Isso permite levar em consideração outras lógicas e racionalidades fundadas na relação com o outro e não só na racionalidade chamada 
«econômica», ou seja, o engodo do lucro (Benería, 1998). É portanto compatível com a análise feminista da economia uma vez que a presença simultânea desses quatro princípios não é considerada apenas uma característica exclusiva das economias «primitivas», mas sim reconhecida nos sistemas atuais de produção, intercâmbio, financiamento e consumo (Lucas Dos Santos, 2016); e uma vez que o encastramento dos mercados contemporâneos num «substrato ético» (Fraser, 2013) da sociedade, que pode ser opressivo, é reconhecido e questionado (ibid., Waller e Jennings, 1991).

Esses caminhos foram raramente explorados pela análise da economia solidária que se mantém focalizada na caracterização de seus princípios, nas tensões entre eles e nas condições de institucionalização de uma economia plural (Hillenkamp e Laville, 2013). Ademais, a distinção entre mercantil e não mercantil é raramente colocada em paralelo com a distinção, relacionada mas diferente, entre produção e reprodução, que é central nas abordagens feministas (Guérin, Hersent e Fraisse, 2011).

\section{TRANSFORMAÇÃO SOCIAL: UMA CONCEPÇÃO RADICAL, GRADUAL E PLURAL}

A crítica da modernidade capitalista combinada à importância da escala local, conduz a uma concepção da transformação social em tensão, que é ao mesmo tempo radical e gradual. A crítica das consequências, principalmente sociais e ambientais, da racionalidade e dos modos de acumulação capitalistas, leva à proposição de uma modernidade democrática que contesta radicalmente a modernidade capitalista e sua base materialista. Assim, o horizonte da economia solidária pode ser descrito como uma inversão de valores, como as cartas e declarações testemunham, que requer novas concepções da riqueza. Esse horizonte estabelece uma distância com certas correntes feministas e se aproxima com outras, em particular o feminismo marxista, que analisa as condições materiais da dominação patriarcal, os mecanismos de reprodução das desigualdades e as relações sociais que sustentam a prosperidade capitalista. Enquanto algumas correntes consideram a emancipação pautada no assalariamento ou ao menos nas atividades remuneradas, outras procuram que fosse revalorizado o trabalho invisível das mulheres excluídas, repensando assim a questão teórica do valor.

Se a visão da transformação social na economia solidária é radical por sua crítica ao capitalismo e pelos valores, modelos e instituições democráticas aos quais ela aspira, ela não deixa de ser gradual na medida que presta atenção à escala local e à pluralidade de princípios econômicos. Certamente, em relação a esse ponto, diferenças consideráveis existem, principalmente sobre considerar a pluralidade em termos de complementaridade e de hibridação de recursos - como nas teorias do terceiro setor-, ou em termos de conflitualidade que invocam uma transformação material e subjetiva das relações sociais - como na teoria da colonialidade do poder (Quijano, 2008; Aguinaga, 2014) —. Mas em geral, as abordagens da economia solidária compartilham da crença sobre o potencial de transformação social e de emancipação das alternativas plurais ao capitalismo, em oposição à alternativa do socialismo centralizado (Sousa Santos e Rodriguez, 2013).

Essa postura é, contudo, indissociável de uma apreciação crítica sobre a viabilidade dessas alternativas, e deve ser combinada a um olhar sobre as mudanças possíveis que não se limitam ao que existe de fato. Por um lado, é verdade que as iniciativas da economia solidária são 
frequentemente emergentes e frágeis, a fortiori as iniciativas de mulheres que se formam em contextos hostis. Elas geralmente não têm a transformação social como objetivo inicial, mas esse objetivo pode aparecer durante processos de ação coletiva que colocam as relações sociais de gênero em perspectiva (Verschuur, 2012; Saussey, 2014). A análise da economia solidária deve levar em conta essa fragilidade das iniciativas, bem como não negligenciar o quanto essas trajetórias podem ser caóticas e desencorajadoras. Por outro lado, a análise - e a açãona economia solidária demanda uma postura utópica, no sentido de uma exploração das potencialidades que visam «a superação dos limites sociais e econômicos impostos na realidade» (Cattani, 2006, p. 653). A armadilha do «fundamentalismo da alternativa», que conduz à «rejeitar proposições que, nascidas dentro do capitalismo, abrem mesmo assim o caminho a uma orientação não capitalista e criam enclaves de solidariedade dentro do sistema» (Sousa Santos e Rodriguez, 2013, p. 133) só pode ser evitada pela «hermenêutica da emergência» que substitui a hermenêutica do ceticismo (ibid.).

Essa postura gradual converge com algumas posições feministas, principalmente as do feminismo popular e do local feminism - feminismo local一, que enfatizam a capacidade de ação das organizações de mulheres nos seus territórios de vida, sem necessariamente ter como objetivo principal acabar com o sistema patriarcal ou capitalista. As zonas negligenciadas pela modernização, especialmente o «conjunto disparate de práticas e registros econômicos que estão ao mesmo tempo dentro e fora do mercado» (Degavre, 2011, p. 78), nas quais as mulheres estão inseridas, ocupam nessa postura um lugar central. Essas posições contém as sementes de uma aproximação entre a economia solidária e os movimentos populares de mulheres dos países do Sul. é essencial observar a sua capacidade de se concretizar nas experiências e de se perpetuar para produzir uma transformação das relações de produção e de gênero.

\section{O OLHAR DOS ESTUDOS FEMINISTAS SOBRE AS ORGANIZAÇÕES DE MULHERES E SUAS PRÁTICAS ECONÔMICAS, SOCIAIS E POLÍTICAS}

A complexidade e a riqueza tanto do pensamento feminista, quanto das experiências das mulheres - diversas, de acordo com as articulações de classe, raça, casta, etc. - foram durante muito tempo desconhecidas, sobretudo nos estudos econômicos. As práticas e reflexões sobre as organizações de mulheres, frequentemente invisíveis ou consideradas insignificantes e sem legitimidade acadêmica, alimentaram este pensamento feminista. Encontros, estudos, pesquisas e publicações sobre as lutas e manifestações diversas das organizações de mulheres e movimentos feministas ajudaram no reconhecimento e na compreensão da dimensão de gênero de suas práticas, de suas contribuições teóricas, bem como de seu lugar na história econômica.

\section{ORGANIZAÇÕES DE MULHERES NA HISTÓRIA E NA CONSTRUÇ̃̃O DO FEMINISMO}

Louise Tilly e Joan Scott (1978) mostraram como as historiadoras das mulheres e do gênero mudaram a percepção das problemáticas sociais e a história social. As pesquisas de historiadoras sobre as operárias da indústria de calçados da Nova Inglaterra no século XIx, sobre as fabricantes de cigarros, sobre as operárias na tecelagem de tapetes, ou ainda na fiação de algodão nos países do Sul, revelaram quanto o papel das mulheres nos conflitos laborais ou mesmo 
no processo de industrialização foi negligenciado. Estes estudos também permitiram a análise das diferenças entre as culturas masculinas e femininas de trabalho e as tensões entre o trabalho de operária e o trabalho doméstico. Os trabalhos das historiadoras feministas abriram o caminho para que se estude não somente a elite, mas também as pessoas e as mulheres comuns e as relações sociais de sexo. Esses trabalhos introduzem a categoria de gênero tal qual definiu Scott, focalizando-se no significado, no poder e no/na ator/atriz.

Pôde-se observar a formação de organizações de mulheres cientes das discriminações desde o século XIX, em diversas partes do mundo e em grupos de afiliações diversas. Que sejam grupos de mulheres escravas, operárias ou burguesas, socialistas, pacifistas ou migrantes, essas organizações lutaram pelos direitos das mulheres e contra as desigualdades de poder. Elas reivindicaram a igualdade entre mulheres e homens tanto no espaço público quanto no privado e desenvolveram redes e atividades múltiplas, não somente no campo político e social mas também no campo econômico.

As atividades das organizações de mulheres precederam o aparecimento da palavra feminismo, adotada em 1892, em Paris (Bard, 1999). No início, os movimentos feministas foram associados às lutas pelo direito ao voto das mulheres - na Europa, Estados Unidos, China etc.e também aos movimentos pela paz, durante a Primeira Guerra Mundial. Tanto no Irã quanto na Índia, as associações pela emancipação das mulheres fundadas no começo do século xx e constituídas principalmente de mulheres da elite, reivindicaram o voto das mulheres e a promoção da educação das meninas, exigências que deveriam contribuir com as mudanças reivindicadas. As lutas das operárias, na França (Flora Tristan, 1979 [1838]), na Argentina (Voz de la Mujer, 1897) e em diversos outros países, desde o fim do século xIX, contribuíram com uma visão crítica sobre as relações desiguais com os homens, não somente os patrões, mas também os maridos. As questões prioritárias nas lutas das diferentes organizações ou movimentos foram diversas, de acordo com o pertencimento às diferentes categorias de classe, raça, etnia, os contextos, os países, os momentos históricos.

Nos anos 1960, o movimento das mulheres tomou consciência da opressão específica causada pelo trabalho gratuito e invisível por elas realizado. Os estudos feministas mostraram que as análises que se limitavam às relações de classe, não permitiam explicar a persistência da subordinação das mulheres (Delphy, 1970; León, 1980). Chistine Delphy, em sua teoria sobre o «trabalho doméstico» e o «modo de produção doméstico», colocou o problema da extração do trabalho gratuito das mulheres e a permanência da opressão das mulheres. O patriarcado, como um sistema autônomo de exploração e de dominação, é segundo a autora o «inimigo principal».

Nesse mesmo período, as organizações de mulheres afrodescendentes, migrantes, indígenas ou de castas consideradas inferiores impuseram suas análises, pois consideravam que os movimentos feministas ditos «hegemônicos» não levavam em conta seus pontos de vista, prioridades e condições específicas. Esses grupos desafiaram as representações «coloniais» «da» mulher: subjugada, impotente, relegada às tarefas domésticas, sem capacidade de se organizar e nem de tomar consciência das causas dos problemas que a afetam (Mohanty, 1988; Hill Collins, 2010). O black feminism - feminismo negro- nos Estados Unidos bem como, por exemplo, organizações de trabalhadoras domésticas no Brasil, exigiam mais consideração às condições e às lutas das mulheres negras. 
A influência das organizações de mulheres foi determinante para o desenvolvimento dos estudos feministas, para a constituição de diversas instâncias nacionais e internacionais sobre este tema e para o avanço das legislações nacionais e convenções internacionais sobre os direitos das mulheres. As grandes conferências internacionais de mulheres e pela paz organizadas pelas Nações Unidas, juntamente com seus fóruns paralelos, reuniram milhares de organizações de mulheres, de movimentos e de universitárias feministas possibilitando a constituição de redes como a DAWN (Development Alternatives with Women for a New Era, Alternativas de Desenvolvimento com Mulheres para uma Nova Era), a wLumL (Women Living Under Muslim Law, Mulheres Vivendo Baixo Lei Muçulmana) ou a Marcha Mundial das Mulheres. Essas redes enfatizam tanto os direitos políticos, sociais e culturais quanto os econômicos. As associações e os grupos econômicos de mulheres de base defendiam a ideia do empoderamento, definido inicialmente como processos coletivos de questionamento das relações desiguais de poder e como a construção de práticas políticas e de espaços econômicos de defesa de direitos.

ORGANIZAÇÕES DE MULHERES: DO CAMPO «MULHERES/GÊNERO E DESENVOLVIMENTO» À CRISE DA REPRODUÇÃO SOCIAL

Nas décadas após a Segunda Guerra Mundial, no âmbito do que foi chamado «desenvolvimento», foram criados programas de cooperação que visavam as mulheres em particular, levando à constituição de um campo de saberes sobre «mulheres/gênero e desenvolvimento».

Lembrar as diferentes fases que se sucederam ajuda a compreender a relativa fraqueza ou o enviesamento que existe hoje no estudo das dimensões de gênero das práticas econômicas e sociais das organizações de mulheres. Em um primeiro momento, a questão, relacionada às reivindicações dos movimentos feministas, era reconhecer o trabalho invisível feito pelas mulheres, principalmente aquele feito pelas mulheres camponesas no terceiro mundo (Boserup, 1970; León, 1980; Benería e Sem, 1981). Num segundo momento, os trabalhos se focalizaram nas transformações das relações sociais entre os sexos, associadas à nova divisão internacional do trabalho que vinha ligada à mundialização. Diversos estudos tratavam da integração das mulheres nas indústrias de transformação delocalizadas, da feminização do proletariado, da parte crescente das mulheres na economia informal das cidades e da feminização das migrações (Beneria, 1982; Kabeer, 1995; Federici, 2002). A economia do cuidado foi analisada em relação à nova divisão internacional do trabalho (Verschuur e Reysoo, 2005). Em um terceiro momento, o foco foi nas identidades e nas lutas por direitos a nível doméstico, local ou global, no contexto da mundialização e da nova divisão internacional do trabalho (Mohanty, 1988; Federici, 2002; Viveros, 2002; Molyneux e Razavi, 2005). As perspectivas feministas decoloniais (Verschuur e Destremau, 2012), inspiradas pelos/as pesquisadores/as da América Latina, questionam não somente as dimensões simbólicas, construídas e culturais das relações de gênero, classe e raça, mas também suas dimensões econômicas e sociais.

Contudo, os programas de cooperação se interessaram de maneira instrumental pelas atividades econômicas das mulheres, consideradas como um recurso mal explorado. A partir da década de 80 , os projetos de «geração de renda», às vezes individuais e às vezes coletivos, associados aos programas de ajuste estrutural que já implicavam um aumento do trabalho reprodutivo para as mulheres, resultaram numa sobrecarga geral de trabalho. Confrontados às 
críticas sobre a exploração excessiva das mulheres e sobre o fracasso desses programas, as agências propuseram programas econômicos ditos de empoderamento das mulheres, inspirados nas propostas das organizações de mulheres. Porém, nem o conteúdo desses programas, nem o seu método correspondiam àquelas propostas iniciais. Por causa de seus princípios e valores subjacentes, do seu enfoque frequentemente individualista, do seu método top-down e da inexistência de análises sobre as relações de poder, todo potencial transformador das proposições das organizações de mulheres foi esvaziado nesses programas. Por outro lado, as discussões sobre o potencial de empoderamento ou de emancipação das mulheres devido à sua integração ao mercado de trabalho assalariado não foram objeto de um consenso entre as feministas (Kabeer, 1987, 1995). A ênfase desses programas era geralmente dada às atividades produtivas, sem considerar o trabalho reprodutivo.

A crise da reprodução social — crises econômicas, e o fato de o Estado não assumir as suas responsabilidades - aumentou consideravelmente as atividades das mulheres subalternas nessa área. Diversos projetos de assistência — planos sociais governamentais, projetos de cooperação- visaram especificamente as mulheres — consideradas como responsáveis pelo bem-estar da família - para que elas se encarreguem das tarefas de reprodução social. Assim, vimos florescer projetos de apoio à atividades coletivas nessa área, concebidos muitas vezes de maneira espontânea ou inscritos em planos sociais, como a alimentação - comedores populares, distribuição de cestas básicas—, a gestão do lixo, a movimentação das creches - madres comunitárias ${ }^{1}$ - etc. Esses múltiplos projetos eram vistos como atividades da esfera reprodutiva, associados ao feminino e, de maneira geral, realizados por mulheres de condição subalterna, mal ou não remuneradas. Os movimentos feministas raramente se interessaram por esses projetos, às vezes até se opuseram a eles, considerando que fortaleciam a subordinação das mulheres, sua exploração e não permitiam a transformação das relações de gênero. Alguns, no entanto, tiveram um efeito transformador devido aos espaços econômicos, de negociação e de poder que indiretamente abriram. Porém, esse efeito foi frequentemente efêmero por conta dos efeitos negativos das políticas públicas ou da concorrência com outros atores econômicos situados em um lugar mais vantajoso do processo de globalização (Verschuur, 2012).

Apesar destas tendências, várias atividades econômicas de coletivos de mulheres também se ampliaram. Pode-se evocar exemplos como as iniciativas de construção popular no Brasil (Bisilliat, 1995, p. 175), as oficinas coletivas em Lima, no Peru (Ypeij, 2002), as práticas de tontina ou alguns Grupos de Interesse Económico na África (Guérin, 2003; Hainard e Verschuur, 2003), as iniciativas de grupos de autoajuda ou grupos afiliados à SEWA na índia ou grupos de tecelagem no Sri Lanka (Postel e Schrijvers, 1980), as atividades de grupos de mulheres comerciantes na ferrovia Bamako-Dakar (Lambert, 1993) ou os grupos de comércio justo das mulheres indígenas na Bolívia (Charlier, 2011; Hillenkamp, 2012). Essas iniciativas coletivas colocaram a articulação entre trabalho produtivo e reprodutivo e as categorias de trabalho, valor e poder no centro da reflexão, inspirando assim o pensamento feminista.

\section{DAS ORGANIZAÇÕES DE MULHERES À ECONOMIA SOLIDÁRIA}

As organizações de mulheres e os movimentos feministas participaram de maneira ampla nas contestações das ordens ideológicas, políticas, econômicas, ambientais, sociais, familiares e 
de gênero sobre as quais se apoia a mundialização do capitalismo. Elas contestaram o declínio das ações públicas nas políticas sociais, as degradações ambientais, a desvalorização do trabalho das mulheres, as desigualdades da nova divisão internacional do trabalho e o acesso aos espaços de poder. Elas também desenvolveram práticas econômicas que não são dissociadas do social e que merecem ser melhor analisadas tanto pelas/os economistas, antropólogas/os e sociólogas/os feministas, como pelas/os especialistas em economia solidária.

Se trata então de aprofundar e criar convergências, de aproximar os quadros conceituais e as categorias de análise dessas diferentes abordagens para avançar na análise das questões centrais em torno da organização da reprodução social no contexto da mundialização. Basear-se na análise dessas experiências pode contribuir para a formulação de modelos diferentes, para a constituição de relações sociais que não se fundamentam na exploração do trabalho de pessoas de gênero, classe ou raça de categorias subalternas. Que levam em consideração o nível local, mas também o global, o imediato e também o longo prazo. Em último caso, se trata de recolocar as questões sobre a organização da reprodução social e do poder no centro da análise.

\section{ALGUMAS PISTAS DE INVESTIGAÇÃO PARA UMA REFLEXÃO TRANSVERSAL}

Esse rápido levantamento do quadro analítico da economia solidária e dos estudos feministas nos sugere uma pista dupla para a investigação transversal.

\section{A PRODUÇÃO E A REPRODUÇÃO NA ES}

Diante da nova divisão internacional do trabalho, das políticas de austeridade e também da urgência ecológica, a questão da articulação entre produção e reprodução se mantém extremamente atual, ao mesmo tempo em que adquire formas inéditas. Como mencionamos no tópico precedente, a pesquisa feminista não cessa de denunciar a renovação das formas de exploração. Ao mesmo tempo, observam-se também iniciativas inovadoras que buscam compartilhar, revalorizar e também des-domesticar as atividades de reprodução — no sentido de tirá-las da esfera doméstica一. Essa «des-domesticação» pode tomar duas formas: a organização das atividades de reprodução de uma maneira original, ou a instauração de formas inéditas de produção e de relação ao trabalho - a economia plural mencionada na primeira parte- que facilitam igualmente as atividades de reprodução. Desta forma, essas atividades não se realizariam no âmbito das relações sociais de tipo doméstico, sem com isso realizarem-se no âmbito das relações sociais capitalistas. Assim, oferecem alternativas às duas armadilhas recorrentes da esfera reprodutiva: por um lado a gratuidade e por outro a mercantilização.

Geralmente, o tema da reprodução social não é suficientemente levado em conta nas discussões sobre as alternativas, que permanecem focalizadas na existência de uma esfera produtiva plural. No entanto, a reprodução social se encontra na essência das práticas alternativas e, por isso, merece um lugar central nestas discussões. Essa questão foi esboçada em um livro coletivo em francês (Guérin, Hersent e Fraisse, 2011), mas as contribuições das pesquisas feministas devem permitir um avanço maior. A seguinte lista, não exaustiva, de questões oferece algumas pistas para a reflexão e a análise.

- A definição de categorias é o primeiro grande desafio. Como abordar e definir a diversidade 
de atividades que são geralmente consideradas como de reprodução, como o cuidado do outro, o cuidado com a natureza e o trabalho sexual? Os significados habituais incluem a reprodução biológica e econômica, a reprodução da força de trabalho e a reconstituição das relações e instituições sociais necessárias para a organização dos indivíduos (Meillassoux, 1975). Podemos adotar uma visão mais ampla, adotando, por exemplo, a noção da reprodução ampliada da vida (Coraggio, 1998; Degavre, 2011)?

- Ora essencializadas por sua contribuição ao vínculo social, ora denunciadas enquanto fontes de opressão e dominação, as atividades de reprodução devem ser pensadas em toda a sua complexidade: provavelmente mais do que em qualquer outra prática, elas combinam relações desiguais de poder, obrigação, mas também afeto e emoções positivas (Folbre, 1997). Essa combinação é resultado das construções sociais de gênero, que associam a feminilidade à doação de si. O gênero possibilita a compreensão da maneira como essa forma de exploração do trabalho se mantém, mas também nos permite ir além de uma análise unicamente material, incluindo a reflexão sobre outros valores e se abrindo a outros olhares e representações da riqueza. O estudo das práticas solidárias deve levar em consideração essa multiplicidade e ambiguidade - da mesma forma que deve estar atento à maneira como essa multiplicidade se manifesta, em função das relações sociais no âmbito das quais se realizam essas práticas.

- Como, por outro lado, abordar e desenvolver as práticas cuja lógica essencial é a garantia dos meios de subsistência e que não se inscrevem na oposição entre produção e reprodução social oriunda no modo de produção capitalista? De que maneira e sob quais condições se pode superar essa oposição? A economia plural e/ou a reorganização da reprodução social podem ser vias possíveis? Os contextos em que a separação entre as esferas produtivas e reprodutivas têm sido limitadas podem favorecer essa superação e se tornarem fontes de inspiração para a ação e a reflexão sobre as alternativas? Quais são as relações de poder e como se reconstroem as relações de gênero nestes contextos?

- Na análise dos efeitos produzidos, como combinar a diversidade dos critérios de apreciação e das escalas de análise com suas eventuais contradições? Na microescala, como pensar os efeitos dessas iniciativas na vida cotidiana das mulheres e homens, seja em termos de reapropriação dos meios de produção e reprodução ou em termos de satisfação individual ou coletiva - ou inversamente, de privação e alienação-, e mais amplamente, de maneira a fazer sentido para as mulheres e os homens? Na macroescala, em que medida essas iniciativas contribuem para a contestação da ordem dominante ou, pelo contrário, perpetuam ou até reforçam os mecanismos estruturais da exploração e da hierarquia, seja do ponto de vista material das relações sociais ou do ponto de vista das identidades e subjetividades?

\section{UMA RELAÇÃo MÚLTIPLA COM A POLÍTICA}

Uma das particularidades das iniciativas de Es é a sua dimensão política. Porém, essa dimensão reveste formas diversas que são frequentemente invisíveis e desvalorizadas porque acontecem em níveis de ação pouco usuais e porque escapam das categorias de análise geralmente utilizadas. A Es e a pesquisa feminista convergem na ideia de levar em consideração essas diferentes formas de ação política, tanto em suas especificidades quanto em suas multiplicidades.

A Es focaliza na deliberação que acontece em espaços públicos em diferentes escalas. No 
nível local, trata-se de «espaços públicos de proximidade» (Eme e Laville, 2006), cujo papel possibilita que as diferentes partes interessadas possam construir conjuntamente os bens e serviços propostos — sua natureza, seu preço, o público alvo, etc.—, criando assim uma alternativa à regulação pelo mercado que se baseia somente na solvabilidade dos utilizadores e consumidores. Além disso, esses espaços podem representar um papel fundamental na socialização, conscientização, aprendizagem e no questionamento das identidades das mulheres e homens.

Em seguida, esses espaços de proximidade se articulam com espaços de nível intermediário, onde, na interação com os poderes públicos, as demandas da Es são aglutinadas e regulamentadas, como ilustram bem as redes brasileiras de economia solidária (França Filho, 2006). O papel desses espaços consiste em institucionalizar as práticas, levá-las ao conhecimento do poder público, manifestar as possíveis necessidades não reconhecidas em uma escala maior, pesar na elaboração das políticas públicas ou de medidas legislativas e regulamentárias, ou ainda modificar as regras do jogo do mercado. Ao mesmo tempo, os processos de institucionalização comportam um risco real de instrumentalização e de distorção da Es pelos poderes públicos. Os espaços públicos não são isentos de fragilidades e maus funcionamentos. Eles são constituídos de atritos, tensões e compromissos permanentes entre interesses individuais e coletivos, entre práticas locais e estruturas estabelecidas. Eles também supõem a existência de intermediários, de interfaces e de guias - indivíduos e organizações-cujo papel é ao mesmo tempo complexo e ambíguo.

Já na pesquisa feminista, a ênfase é dada à diversidade de formas de engajamento - relacionada com as diferentes imbricações de gênero, classe, raça, etc.- e à diversidade de correntes de feminismo, marcando assim sua diferença com a definição clássica dos movimentos sociais. Da mesma maneira, a análise feminista recusou a oposição público/privado, afirmando que o pessoal é público, mostrando por exemplo como as questões de ordem doméstica levam as mulheres ao engajamento na luta política.

Nessa etapa da nossa reflexão, é necessário delinear duas formas - tipos ideais - de engajamento, das quais os seguintes exemplos são emblemáticos.

Por um lado, existem práticas econômicas alternativas que tentam, ao mesmo tempo, influenciar a política através do que poderíamos chamar de uma «reinvenção cultural da política»: essas iniciativas não visam necessariamente derrubar a ordem patriarcal, nem o sistema "capitalista», e se definem como «lugares onde sujeitos - homens e mulheres - constroem desde dentro, nesse território, soluções e esboços de novas relações entre homens e mulheres, sem esperar» (Verschuur, 2005, p. 52). Podemos citar o exemplo de grupos femininos que podemos encontrar em diversos países da África do Oeste sob o rótulo de Grupos de Interesse Econômico. Em suas atividades de artesanato, de produção ou de financiamento, esses grupos defendem uma maior consideração dos seus direitos pelas municipalidades ou mesmo pelo Estado central. Podemos citar também o caso das cooperativas de produção que lutam pelo reconhecimento do preço justo de seus produtos (Charlier, 2011) ou os casos das cantinas coletivas que reivindicam às autoridades públicas a utilidade social de suas atividades e a remuneração justa do trabalho das mulheres (Angulo, 2011).

Por outro lado, observamos práticas de reivindicação e de luta, muitas vezes radicais, que são acompanhadas pela oferta de serviços concretos. Essa articulação pode ser o resultado 
de uma convicção profunda: a de que a mudança social supõe uma articulação permanente entre «luta e desenvolvimento» (Kabeer, 2011). Ou de uma perspectiva mais pragmática, onde a oferta de serviços cotidianos é um fator determinante para a própria existência das lutas, especialmente quando elas são radicais, percebendo a conflitualidade como um elemento constitutivo da democratização, e inscritas no longo prazo. A luta política só é possível quando articulada a práticas que garantam a sobrevivência cotidiana daquelas e daqueles que participam (Rauber, 2002). Observamos aqui o papel da reprodução social no engajamento político, uma questão que é claramente sub-explorada.

Podemos citar o exemplo das recentes insurreições sociais por falta de alimentos, que têm como característica específica a capacidade de articular revolta e experimentação. Nesses casos, a denúncia dos mecanismos de opressão e exploração acontece simultaneamente às ações concretas, que oferecem vantagens materiais aos participantes ao mesmo tempo em que permitem a construção de novos repertórios de ação e de solidariedade que são necessários nesses momentos de revolta (Guérin e Nobre, 2014). Outras formas de luta e de reivindicação têm a particularidade de se inscreverem a longo prazo e se articularem com formas de auto-organização: homens e mulheres devem inventar, reinventar e se apropriar dos modos populares de gestão das necessidades básicas, como a alimentação. O movimento dos Piqueteros na Argentina é emblemático dessa lógica. Nele combinam-se a ocupação do espaço público durante um longo período, especialmente através do bloqueio de ruas, e a administração das necessidades cotidianas das pessoas, através de cantinas populares, padarias, jardins, escolas maternais, grupos de prevenção da violência doméstica, etc. (Nobre e Freitas, 2011, p. 242).

A continuidade entre práticas econômicas, ações públicas e reivindicações políticas toma formas plurais que necessitam ser exploradas mais detalhadamente, tanto para poder documentar de maneira empírica o seu funcionamento cotidiano, quanto para renovar nossos parâmetros de análise da sua relação com o poder e a política. Duas questões são, nesse caso, essenciais. A primeira é relativa ao papel das mulheres, especialmente as subalternas, nessas iniciativas. A segunda trata da inclusão das reivindicações feministas nas agendas. Essa inclusão é diretamente relacionada à articulação, sempre complexa, entre essas reivindicações e as outras lutas e, por conseguinte, com as alianças possíveis. Redes de Es enquanto redes feministas, ao menos algumas delas, permanecem majoritariamente indiferentes à essas iniciativas locais, ou mesmo as desprezam (Hersent e Guérin, 2014). Renovar essas observações introduzindo novas categorias de análise aptas a reconhecer a capacidade de inovação é essencial. As pistas propostas aqui devem permitir, nós esperamos, avançar nessa direção.

\section{NOTAS}

1 Uma versão extensa deste texto foi publicada em francês baixo o título «économie solidaire et théories féministes: pistes pour une convergence nécessaire», na Revista de Economia Solidária, Ponta Delgada, n. ${ }^{\circ}$ 7, p. 5-43, outubro de 2014. A presente versão em português se apoia na tradução inicial realizada por Nathalia Capellini a pedido da Sempreviva Organização Feminista (sof, São Paulo, Brasil). A revisão final foi realizada por Lais Meneguello Bressan. Agradecemos a ambas pela colaboração.

2 Householding no texto original em inglês, traduzido em português como «domesticidade». Preferimos aqui o termo de autossuficiência que explica o fundamento desse princípio, inspirado na distinção de 
Aristóteles entre produção para o uso e produção para o ganho (Hillenkamp, 2013). 3 N. T.: mães crecheiras

\section{REFERÊNCIAS}

Aguinaga, M. (2014). La Economía Solidaria en Ecuador entre la colonialidad del poder y el Buen Vivir desde una mirada feminista crítica. Revista de Economia Solidária, 7, 116-149.

Angulo, N. (2011). Cantines populaires: sécurité alimentaire et exercice de la citoyenneté au Pérou. Dans I. Guérin, M. Hersent y L. Fraisse (Orgs.) Femmes, économie et développement: De la résistance à la justice sociale (pp. 221-236). Paris, France: IRD éditions, Erès.

Bard, C. (1999). Un siècle d’anti-féminisme. Paris, France: Fayard.

Beneria, L, and Sen, G. (1981). Accumulation, Reproduction, and women's role in economic development: Boserup revisited. Signs: Journal of women in culture and society, 7(2), 279298.

Beneria, L. (1982). Women and development. the sexual division of labor in rural societies. New York, UsA: Praeger.

Benería, L. (1998). Karl Polanyi, la construcción del mercado global y la «diferencia» de género. Mientras tanto, 71, 81-101.

Bisilliat, J. (1995). La construction populaire au Brésil: une expérience à Sao Paulo. Paris, France: Karthala. Boserup, E. (1993 [1970]). Mujer y el desarrollo económico. Madrid, España: Minerva Ediciones.

Castro-Gomez, S. y Grosfoguel, R. (2007). El giro decolonial. Reflexiones para una diversidad epistémica más allá des capitalismo global. Bogotá, Colombia: IEsco, Siglo del Hombre Editores.

Cattani, A. D. (2006). Utopie. Dans J.-L. Laville, A. D. Cattani (Org.), Dictionnaire de lautre économie (pp. 652-661). Paris, France: Gallimard.

Charlier, S. (2011). Empoderamiento des femmes par l'économie populaire solidaire: participation et visibilité des femmes en Bolivie. Dans I. Guérin, M. Hersent et L. Fraisse (Coords.), Femmes, économie et développement: De la résistance à la justice sociale (pp. 155-184). Paris, France: IRD éditions, Erès.

Coraggio, J. L. (1998). El trabajo desde la perspectiva de la Economía Popular. En Economía Popular Urbana: una nueva perspectiva para el desarrollo local. Buenos Aires, Argentina: Instituto del Conurbano-UNGs.

Coraggio, J. L. (2010). La economía social y solidaria como estrategia de desarrollo en el contexto de la integración regional latinoaméricana. Revista de Economia Solidária, 2, 12-23.

Degavre, F. (2011). La pensée «femmes et développement». Critique des fondements et pistes pour reconstruire un point de vue féministe croisé Nord/Sud. Dans I. Guérin, M. Hersent et L. Fraisse (Coords.), Femmes, économie et développement: De la résistance à la justice sociale (pp. 63-84). Paris, France: IRD éditions, Erès.

Degavre, F. et Lemaître, A. (2008). Approches substantives de l'économie : des outils pour l'étude des organisations d'économie sociale. Interventions économiques, 38, 1-16.

Delphy, C. (1970). L'ennemi principal. Partisans, n. ${ }^{\circ}$ spécial «Libération des femmes», (s. d. ).

Destremau, B. et Verschuur, C. (Dirs.). (janvier-mars, 2012). Féminismes décoloniaux, genre et développement. Revue Tiers Monde, 209, (s. d.).

Eme, B. et Laville, J.-L. (2006). Économie solidaire (2). Dans J.-L. Laville, A. D. Cattani (Orgs.), Dictionnaire de l'autre économie (pp. 303-312). Paris, France: Gallimard.

Federici, S. (2002). Reproduction et lutte féministe dans la nouvelle distribution internationale du travail. Dans C. Verschuur et F. Reysoo (Dirs.), Genre, mondialisation et pauvreté. Cahiers genre et 
développement (pp. 45-73). Paris, France: L’Harmattan.

Ferber, M. and Nelson, J. (1993). Beyond economic man: feminist theory and economics. Chicago, UsA: The University of Chicago Press.

Folbre, N. (1997). De la différence des sexes en économie politique, Paris, France: Ed. Des femmes.

França Filho, G. (2006). Políticas públicas de economia solidária no Brasil: características, desafios e vocação. Em G. C. França Filho, J.-L. Laville, J.-P. Magnen e A. Medeiros (Coords.), Ação Pública e economia solidária - uma perspectiva internacional (pp. 259-267). Salvador, Brasil: EDUfrgs/EDUfBA.

Fraser, N. (2013). Marchandisation, protection sociale, émancipation: vers une conception néo-polanyienne de la crise capitaliste. Dans I. Hillenkamp et J.-L. Laville (Orgs.), Socioéconomie et démocratie. L'actualité de Karl Polanyi (pp. 39-63). Toulouse, France: IRD éditions, Erès.

Gibson-Graham, J. K. (2005). Surplus Possibilities: Postdevelopment and Community Economies. Singapore Journal of Tropical Geography, 26(1), 4-26.

Guérin, I. (2003). Femmes et économie solidaire. Paris, France: La Découverte.

Guérin, I. et Nobre, M. (2015). Léconomie solidaire revisitée à la lumière du genre: outil de changement social ou reproduction de la subordination féminine? Dans Ch. Verschuur, I. Guérin, H. GuetatBernard (Orgs.), Sous le développement, le genre? Marseille, France. IRD éditions, Erès.

Guérin, I. Hersent, M. et Fraisse L. (Dirs.) (2011). Femmes, économie et développement. De la résistance à la justice sociale. Paris, France: IRD éditions, Erès.

Hainard, F. and Verschuur, C. (august, 2003). Gender relations and grass-roots urban movements. International Social Science Review, 177, 473-488.

Hersent, M. et Guérin, I. (2014). Une aproche internationale des initiatives des femmes dans l'ESS. Revista de Economia Solidária, 7, 45-62.

Hill Collins, P. (2010). La construction sociale de la pensée féministe. Dans C. Verschuur (Coord.), Genre, postcolonialisme et diversité des mouvements de femmes. Cahiers genre et développement. Paris, France: L'Harmattan.

Hillenkamp, I. (2012). Economía solidaria y transformación social: pluralidad y tensiones. En B. MarañonPimentel (Org.), Solidaridad económica y potencialidades de transformación en América Latina: una perspectiva descolonial (231-258). Buenos Aires, Argentina: CLAcso.

Hillenkamp, I. (2013). Le principe de householding aujourd'hui. Discussion théorique et approche empirique par l'économie populaire. Dans I. Hillenkamp et J.-L. Laville (Orgs.), Socioéconomie et démocratie. L'actualité de Karl Polanyi (pp. 215-239). Toulouse, France: IRD éditions, Erès.

Hillenkamp, I. et Laville, J.-L. (Coord.) (2013). Socioéconomie et démocratie. Lactualité de Karl Polanyi. Toulouse, France: IRD éditions, Erès.

Kabeer, N. (1987). Reversed realities: Gender hierarchies in development thoughts. London, UK: Verso.

Kabeer, N. (2011). Emploi informel, initiatives syndicales et genre. Dans I. Hillenkamp et J.-L. Laville (Orgs.), Socioéconomie et démocratie. Lactualité de Karl Polanyi (pp. 255-288). Toulouse, France: IRD éditions, Erès.

Kabeer, N. (September, 1995). Necessary, sufficient or irrelevant? Women, wages and intra-household power relations in urban Bangladesh. Institute of Development Studies. Working Paper, 25, (s. d.).

Kergoat, D. (2001). Le rapport social de sexe. De la reproduction des rapports sociaux à leur subversion. Actuel-Marx, 30, 85-100.

Lambert, A. Les commerçantes maliennes du chemin de fer Dakar-Bamako. Dans G. Emmanuel et P. 
Labazée (Orgs.), Grands commerçants d'Afrique de l'Ouest. Logiques et pratiques d'un groupe d'hommes d'affaires contemporains (pp. 37-70). Paris, France: Karthala-оRsтом.

Laville, J.-L- (2010). Politique de lassociation. Paris, France: Seuil.

Laville, J.-L. (2013). Avec Polanyi et Mauss. Vers une théorie de la démocratie et de léconomie plurielles. Dans I. Hillenkamp et J.-L. Laville (Orgs.), Socioéconomie et démocratie. L’actualité de Karl Polanyi (pp. 271-300). Toulouse, France: IRD éditions, Erès.

Lemaitre, A. (2013). 'Popular cooperatives' and local development in South-East Brazil: Towards socioeconomic pluralism. In I. Hillenkamp, F. Lapeyre and A. Lemaître (Dirs.), Securing livelihoods. Informal economy practices and institutions (pp. 25-46). Oxford, uк: Oxford University Press.

León, M. (1980). Mujer y capitalismo agrario. Bogotá, Colombia: ACEP.

Lucas Dos Santos, L. (maio, 2016). Polanyi through the lens of Epistemologies of the South and Postcolonial Feminist Economics: different glances at the concept of disembeddedness. Documento apresentado em 2. ${ }^{\text {do }}$ EMEs-Polanyi International Seminar. Paris, France.

Mauss, M. (1968 [1923]). Essai sur le don. Forme et raison de l'échange dans les sociétés archaïques. Sociologie et anthropologie, (s. d.), 143-279.

Mohanty, Ch. T. (1988). Under Western Eyes: Feminist Scholarship and Colonial Discourses. Feminist Review, 30, 61- 88.

Molyneux, M. (1997). Prefácio a La Voz de la Mujer. Periódico comunista-anárquico [1896-1897]. Buenos Aires, Argentina: Universidad Nacional de Quilmes.

Molyneux, M. and Razavi, Sh. (2005). Beijing plus ten: an ambivalent record on gender justice. Development and Change, 36(6), 983-1010.

Nelson, J. (2012). Poisoning the well, or how economy theory damages moral imagination. In M. George and M. Deirdre (Coords.), Handbook on Professional Economic Ethics. Oxford, uk: Oxford University Press.

Nobre, M. et Freitas, Y. (2011). Possibilités et limites de la construction de légalité de genre dans léconomie solidaire. Dans I. Guérin et al., (op. cit.) (pp. 237-254).

Polanyi, K. (1983 [1944]). La Grande Transformation. Aux origines politiques et économiques de notre temps. Paris, France: Gallimard.

Postel-Coster, E. and Schrijvers, J. (Eds.) (1980). A Woman's mind is longer than a kitchen spoon. Report on women in Sri Lanka. Research project women and development. (s. d.).

Quijano, A. (2008). «Solidaridad» y capitalismo colonial/moderno. Otra Economía, 2, 12-16.

Rauber, I. (2002). Mujeres piqueteras: el caso de Argentina. En F. Reysoo (Coord.), Economie Mondialisée et Identités de Genre. Genève, Suisse: UnESco.

Razavi, Sh. (2012). World development report 2012: Gender equality and development. An opportunity both welcome and missed. Development and Change, 43, 423-437.

Razeto, L. (1997). Factor «C». Barquisimeto, Argentina: (s. d.).

Sarria Icaza, A. et Tiriba, M. L. (2006). Économie populaire. Dans J.-L. Laville, A. D. Cattani (Orgs.), Dictionnaire de lautre économie (pp. 258-268). Paris, France: Gallimard.

Saussey, M. (2014). Women's collective action, solidarity and gender in Burkina Faso. Revista de Economia Solidária, 7, 101-115

Servet, J. M. (2013). Le principe de réciprocité aujourd'hui. Un concept pour comprendre et construire léconomie solidaire. Dans I. Hillenkamp et J.-L. Laville (Orgs.), Socioéconomie et démocratie. L'actualité de Karl Polanyi (pp. 187-213). Toulouse, France: IRD éditions, Erès. 
Sousa Santos, B. de, et Rodríguez Garavito, C. (2013). Alternatives économiques: les nouveaux chemins de la contestation. Dans I. Hillenkamp et J.-L. Laville (Orgs.), Socioéconomie et démocratie. Lactualité de Karl Polanyi (pp. 127-147). Toulouse, France: IRD éditions, Erès.

Tilly, L. et Scott, J. W. (2002, [1978]). Les femmes, le travail et la famille. Paris, France: Payot et Rivages. Tristán, F. (1979, [1838]). Les pérégrinations d’une paria. Paris, France: Maspero.

Vázquez, G. (2013). Self-managed work, social protection, and community development: The case of the UsT Cooperative (Argentina). In I. Hillenkamp, F. Lapeyre and A. Lemaître (Dirs.), Securing livelihoods. Informal economy practices and institutions (pp. 64-7). Oxford, Uk: Oxford University Press.

Verschuur, Ch. (2005). Mouvements de base, genre et justice sociale, réinvention culturelle du politique. Dans F. Hainard et Ch. Verschuur, Mouvements de quartier et environnements urbains. La prise de pouvoir des femmes dans les pays du Sud et de l'Est (pp. 49-83). Paris, France. Karthala.

Verschuur, Ch. (2012). Raccommodages de la pauvreté ou engagements féministes dans les quartiers populaires de San Cayetano et Gamboa en Amérique latine. Autrepart, 61, 175-19o.

Verschuur, Ch. (2013). Reproduction sociale et care comme échange économico-affectif. Larticulation des rapports sociaux dans l'économie domestique et globalisée. Dans Ch. Verschuur et Ch. Catarino (Dirs.) Genre, migrations et globalisation de la reproduction sociale. Cahiers Genre et Développement (pp. 23-39). Genève-Paris: L'Harmattan.

Verschuur, Ch. (Dir.) (2000). Quel genre d'homme? Construction sociale de la masculinité, relations de genre et développement. Actes des colloques de L'IUED. Commission nationale suisse pour L'UnEsCoDDC-IUED, Genève-Berne. (s. d.).

Viveros, M. (2002). De quebradores y cumplidores. Sobre hombres, masculinidades y relaciones de género en Colombia. Bogotá, Colombia: Universidad Nacional de Colombia.

Waller, W. and Jennings, A. (1991). A feminist institutionalist reconsideration of Karl Polanyi. Journal of Economic Issues, (25)2, 485-497.

Wanderley, F. (2013). El concepto de pluralidad económica: una lectura desde Bolivia. Ponencia presentada en el xxix Congreso Latinoamericano de Sociología. Santiago de Chile, Chile.

Ypeij, A. (2002). Ateliers collectifs: une alternative pour les femmes dans les quartiers pauvres de Lima. Dans C. Verschuur et F. Reysoo (Coords), Genre, mondialisation et pauvreté (pp. 99-105). Paris, France: L'Harmattan. 


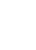

